\title{
PerCursos
}

\section{Disco Animals do Pink Floyd: uma distopia sobre animalização do sistema capitalista e a democracia liberal burguesa}

\section{Resumo}

A distopia é um gênero narrativo explorado pela literatura, cinema, teatro, jogos eletrônicos e música. Caracteriza-se como contrário da utopia (lugar imaginário ideal), onde as relações humanas tornam-se insuportáveis, ao exagerar determinadas questões acerca do contexto no qual foi produzida. São comuns elementos como solidão, cenários pós-apocalípticos, guerras e o totalitarismo, expresso na caça às minorias, na violência e na vigilância extremas. Em 1977, a banda britânica de rock n' roll Pink Floyd lançou o álbum conceitual Animals, inspirado na obra Revolução dos Bichos, de George Orwell, contendo cinco músicas com nomes de animais: ovelhas, porcos e cães. Com base na aproximação metodológica entre História e música, busca-se uma análise do álbum no contexto da década de 1970, ou seja, o surgimento de uma nova onda conservadora frente à recente crise do capitalismo, e um desencantamento do mundo moderno, que animaliza as pessoas e as relações sociais. Para tal, foram utilizados conceitos e teorias de autores como Murray Schafer, Marcos Napolitano e Robert Walser.
Franco Santos Alves da Silva

Doutor em História Cultural pela

Universidade Federal de Santa

Catarina - UFSC. Mestre em

História Contemporânea pela

Universidade do Porto, Portugal. Brasil

alvesfranco@hotmail.com

Palavras-chave: Distopia. Pink Floyd (Conjunto musical). Rock.

\section{Para citar este artigo:}

SILVA, Franco Santos Alves da. Disco Animals do Pink Floyd: uma distopia sobre animalização do sistema capitalista e a democracia liberal burguesa. PerCursos, Florianópolis, v. 21, n.47, p. 79 - 107, set./dez. 2020. 


\title{
Pink Floyd's Animals album: a dystopia about the animalization of the capitalist system and bourgeois liberal democracy
}

\begin{abstract}
Dystopia is a narrative genre explored by literature, cinema, theater, electronic games, and music. It is characterized as opposed to utopia (ideal imaginary place), where human relations become unbearable by exaggerating certain questions about the context in which it was produced. Elements such as loneliness, post-apocalyptic scenarios, wars, and totalitarianism are common, expressed in the hunt for minorities, in extreme violence and surveillance. In 1977, British rock ' $n$ ' roll band Pink Floyd released the concept album Animals, inspired by George Orwell's Animal Farm, containing five songs with animal names: sheep, pigs, and dogs. Based on the methodological approach between History and music, an analysis of the album is sought in the context of the 1970s, that is, the emergence of a new conservative wave in the face of the recent crisis of capitalism and a disenchantment of the modern world, which animalizes people and social relationships. To this end, concepts and theories from authors such as Murray Schafer, Marcos Napolitano, and Robert Walser were used.
\end{abstract}

Keywords: Dystopia. Pink Floyd. Rock. 


\section{O Pink Floyd e a produção do disco Animals}

O Pink Floyd surgiu em Londres, em 1965, com os amigos Roger Keith "Syd" Barrett (guitarra e vocal), George Roger Waters (contrabaixo e vocal), Richard "Rick" Wright (teclado, órgãos, piano e sintetizadores) e Nicholas “Nick” Mason (bateria). Todos os membros originais eram remanescentes de outros grupos de rock, majoritariamente estudantes de Artes e Arquitetura de Cambridge. A banda era então liderada por Barrett, que compunha as músicas e as letras, ambas com forte característica experimental e psicodélica. ${ }^{1}$ As longas peças, quando apresentadas ao vivo, eram acompanhadas por um aparato de luz e projeções ainda amadoras, mas já consideradas vanguardistas para a época (BLAKE, 2012, p. 97; MASON, 2013, p. 62; POVEY, 2016, p. 37). Barrett deixou a banda em 1968, devido ao agravamento de um quadro de esquizofrenia aliado ao abuso de ácidos lisérgicos.

Durante o ano de 1976, o Pink Floyd não realizou concertos ao vivo e, entre abril e dezembro, os integrantes estavam concentrados em gravar um ambicioso e, segundo veremos nas críticas, soturno décimo disco de estúdio: Animals. Trata-se de um caldeirão conceitual sonoro sob a forma de uma fábula zoomórfica acerca da sociedade capitalista contemporânea. O disco foi lançado no dia 21 de janeiro de 1977, pela EMI Harvest, no Reino Unido, onde alcançou a posição de número dois entre os mais vendidos pela Music Week 'Top 75 Albums'. Nos EUA, o disco foi lançado no mês seguinte pela Columbia, alcançando a terceira posição no US Billboard 'Top LPs \& Tape' (POVEY, 2016, p. 256).

A partir de Animals, tem-se uma maior centralização da concepção e das composições nas mãos de Roger Waters, sendo este o primeiro disco a não ter uma única música feita a partir da colaboração de todos os integrantes. Das cinco músicas, apenas uma tem coautoria de David Gilmour, as demais são todas de Waters. Nessa época, as divergências com Richard Wright começaram. O tecladista, em um documentário para a rede britânica BBC (British Broadcasting Corporation), afirmou que não tinha boas recordações sobre o processo de produção deste trabalho:

\footnotetext{
${ }^{1} \mathrm{O}$ nome da banda mudava constantemente, flutuando entre The Tea Set, Megadeaths e The Abdabs, para The Pink Floyd Sound, nome inspirado nos músicos de blues estadunidenses Pink Anderson e Floyd Council, presentes na coleção de Barrett.
} 
Eu acho que não lutei muito para colocar minhas coisas nele. E eu não tinha nada para colocar [...] Eu penso, eu toquei bem, mas eu não contribuí para a escrita dele e penso que Roger meio que não me deixou fazer isto! (THE PINK FLOYD AND SYD BARRETT STORY, 2001, tradução nossa)

A concepção de Animals ganhou contornos ainda durante a gravação do álbum anterior, Wish You Were Here (1975), enquanto Roger Waters rabiscava em seu caderno um projeto de um filme sobre um mundo distópico com desenhos de máscaras de animais, que não chegou a ser realizado. O grupo já tocava regularmente as canções Raving and Drooling e You Gotta Be Crazy, que nas gravações de Animals foram reformuladas e se tornaram Sheep e Dogs, respectivamente (BLAKE, 2012, p. 241; MASON, 2012, p. 257).

Junto com o lançamento do disco, o grupo criou um documentário com seis capítulos, um por semana, intitulado The Pink Floyd Story, que foi ao ar pela Capital Radio, em 17 de dezembro de 1976. O produtor, Nick Horne, obteve acesso total aos quatro membros da banda, exigindo sua aprovação antes dos programas irem ao ar.

Roger Waters recorda que,

Às vezes, durante o meio da gravação, parecia a coisa certa para unir todos num mesmo vínculo. Recebi a tarefa de reescrever a letra de Raving and Drooling em Sheep, porque Raving and Drooling foi apenas mais um grito, mas um grito bastante incoerente de abuso. Eu tive a ideia de Animals guardada em minha mente durante anos, muitos anos. É, realmente, a mesma ladainha de sempre. (THE PINK FLOYD AND SYD BARRETT STORY, 2001, tradução nossa) ${ }^{3}$

\footnotetext{
2 "I didn't fight very hard to put my stuff on it and I didn't have anything to put in it [...] I think, I played well, but I didn't contribute to the writing of it, and I think also Roger is kind no letting me do that! This was the start of the whole ego I think" (THE PINK FLOYD AND SYD BARRETT STORY, 2001).

3 "Sometimes during the middle of recording it, it seemed like the right thing to tie all together. It gave me the lead to re-write the lyrics to 'Raving and Drooling' into 'Sheep', cos' 'Raving and Droolig' was just another shout, but it was a rather incoherent shout of abuse. l've had the idea of Animals in the back of my mind for years... many years. It's a kind of old chestnut, really" (The Pink Floyd Story, 1977).
} 
O objetivo deste artigo é analisar a narrativa distópica contida no disco Animals, do Pink Floyd, de 1977, relacionando-a com seu contexto de produção. A obra é inspirada no livro A Revolução dos Bichos, de 1945, do inglês George Orwell. Entretanto, enquanto o livro de Orwell faz uma crítica à Revolução Russa, sobretudo à União das Repúblicas Socialistas Soviéticas sob o comando de Josef Stalin, o disco faz uma crítica à democracia liberal burguesa representativa na Inglaterra, como modelo político, e ao capitalismo, enquanto modelo econômico. Pontualmente, o texto fará abordagens a respeito da obra de Orwell, sobretudo no que tange ao caráter distópico. Todavia, não é o objetivo deste artigo fazer um estudo comparado entre as duas obras. Neste sentido, através da análise das canções (junção da parte lírica com o instrumental) e com o aporte teórico de historiadores e musicólogos, serão analisadas as cinco canções que compõem o disco Pigs on the Wing (Part I), Dogs, Pigs (Three Different Ones), Sheep e Pigs on the Wing (Part II) à luz do contexto de crise do capitalismo na década de 1970. Todas as traduções são livres, feitas pelo autor.

Para compreendermos a definição semântica de "distopia", também chamada de antiutopia ou diatopia, é mister perceber a sua antítese, “utopia”, palavra cunhada por Thomas More, em 1516, na obra de mesmo nome. Dividido em dois livros, Utopia tece uma crítica direta à sociedade e à monarquia inglesa da época, enquanto que na segunda o autor descreve, por meio da narração do personagem, e seu alter ego, Rafael Hitlodeu, as maravilhas de uma ilha cuja sociedade funciona perfeita e equilibradamente por meio da divisão das tarefas e ofícios, através de uma valorização do trabalho, onde não há desemprego e não existe propriedade privada e não utiliza-se dinheiro, todos trabalham para o coletivo. Na ilha existe o tratamento humano aos escravos, comedida valorização da religião e do ouro. A partir de então, a palavra "utopia" passou a designar a projeção de um lugar perfeito, no qual a sociedade funcionaria de forma harmônica e ideal. Não obstante, há ainda uma utilização questionável do termo para designar projetos políticos e ideológicos como inalcançáveis e impossíveis (MORE, 2017).

Uma distopia pode ser descrita como uma ficção alocada no futuro ou em um mundo paralelo no qual a vida e as relações sociais tornaram-se insuportáveis ou mesmo intoleráveis. Trata-se de um contexto caótico em que diversos elementos podem estar 
presentes de forma bem definida, ou central, e cuja origem remonta a situações testemunhadas pelo autor em sua própria sociedade. Uma distopia pode apresentar-se sob múltiplas formas, tais como desastres ambientais, violência extrema, colapso social, pobreza exacerbada, repressão policial, sistema político com partido único ou classe opressora, robôs, entre outros. Embora todos esses elementos já existam na sociedade, a distopia tende a exagerar essas nuances e características para além do limite das condições existentes ou mesmo suportáveis.

As projeções distópicas são, sobretudo, fruto da descrença de seus autores no futuro da humanidade baseada em determinados fatores e contextos, que os levam a externar seus medos de forma a repelir tais pontos negativos. As narrativas distópicas ganharam, ao longo do século XX, novos formatos, meios de contato com o púbico e linguagens próprias. Podemos citar o cinema, que viria a adaptar diversos romances, o rádio e outras formas de narrativas literárias, como as histórias em quadrinhos. Neste artigo, veremos uma narrativa distópica a partir da análise musical de um disco e seu significado.

Segundo o musicólogo estadunidense Robert Walser, "muitas pessoas falam sobre ‘significado' de uma música quando o que eles realmente estão discutindo é apenas a letra da canção". Assim, pode-se depreender que o significado verbal é apenas uma fração do que faz com que músicos e fãs respondam e se importem com a música popular (WALSER, 1993, p. 26). Ao pesquisar aspectos do heavy metal, no entanto, o autor propõe uma análise de discurso mais abrangente e específica.

A noção de análise do discurso nos permite prosseguir uma investigação que integre aspectos musicais e sociais da música popular. Ao abordar gêneros musicais como discursos, é possível especificar não apenas certas características formais de gêneros, mas também uma série de entendimentos compartilhados entre os músicos e os fãs sobre a interpretação dessas características. (WALSER, 1993, p. 28)

O discurso estaria presente em todo o universo que envolve cada composição. Assim, os timbres vocais, as distorções da guitarra e mesmo a estrutura musical 
formariam um conjunto de significados ligados a um subgênero específico, como hard core, punk, heavy metal ou rock progressivo. Tal confluência ganharia sentido frente a uma audiência que espera certos elementos, ou padrões, dentro de determinado estilo.

Mas como é possível decodificar o sentido das canções, na intenção de compreender além da mensagem ideológica e da transcrição da letra? Na opinião de Napolitano, existem diversos

[...] vícios que podem ser resumidos na operação analítica, ainda presente em alguns trabalhos, que fragmenta este objeto sociológica e culturalmente complexo, analisando "letra" separada da "música", "contexto" separado da "obra", "autor" separado da "sociedade", "estética" separada da "ideologia". (NAPOLITANO, 2002, p. 8)

O autor ainda afirma que existem dois tipos de parâmetros fundamentais quando se pretende analisar uma canção: os poéticos, ligados à letra; e os musicais, sobre a melodia. Assim, ele separa alguns itens na parte lírica, tais como: a) mote ou tema geral; b) identificação do "eu poético", quem fala e para quem; c) desenvolvimento narrativo; d) tipos de rimas e formas poéticas; e) uso de figuras de linguagem; e f) ocorrência de intertextualidade. Deve-se compreender que dentro de uma canção existem diversos elementos, e uma série de termos que ajudam a decodificar, ainda que de maneira sucinta, o universo musical (NAPOLITANO, 2002, p. 98).

a) Melodia: pontos de tensão/repouso melódico; "clima” predominante (alegre, triste, exortativo, perturbador, lírico, épico etc.); identificação dos intervalos e alturas que formam o desenho melódico (com apoio da partitura); b) Arranjo: instrumentos predominantes (timbres), função dos instrumentos no "clima" geral da canção; identificação do tipo de acompanhamento (homofônico, de tessitura densa ou polifônico, de tessitura vazada e contrapontística); c) Andamento: rápido, lento; d) Vocalização: tipos e efeitos de interpretação vocal, levando-se em conta: intensidade (muito volume/pouco volume), tessitura atingida (graves/agudos); forma de divisão das frases musicais e das palavras que formam a "letra"; ocorrência de ornamentos vocais; e) Gênero musical: geralmente confundido com o "ritmo" da canção (samba, pop/rock, sertanejo etc.); f) Ocorrência de intertextualidade musical (citação 
incidental de partes de outras obras ou gêneros musicais); g) "Efeitos" eletroacústicos e tratamento técnico de estúdio (balanceamento dos parâmetros, texturas e timbres antinaturais). (NAPOLITANO, 2002, p. 98)

O conceito de "paisagem sonora", que busca compreender o ambiente por meio da percepção sônica, também será utilizado neste artigo. Elaborada na década de 1960 por Murray Schafer, a paisagem sonora extrapola a música, sendo composta por sons, ruídos e silêncios de um ambiente, também podendo ser entendida como símbolo de pertencimento de sociedades, cada sociedade com seus sons determinantes e característicos". A paisagem sonoro-musical "é constituída de ruído, som, timbres, amplitude, melodia, textura, que se encontram num cone de tensões, instalado num horizonte acústico" (SCHAFER, 1991, p. 78). Um exemplo ilustrativo desta dinâmica é o fato de que pessoas que vivem próximas a igrejas com campanários regem suas vidas conforme o badalar dos sinos. Nossa hipótese é de que a teoria de Schafer ajudará a compreender os elementos sonoros introduzidos na mixagem de som, e mesmo a ambiência criada pelos teclados de Richard Wright, que ajudam a criar paisagens sonoras e dar profundidade aos personagens, influenciando na experiência e na narrativa contida no disco.

A intertextualidade é uma das principais marcas do álbum Animals. Baseado no livro escrito em 1945, do inglês George Orwell, o disco não tinha como objetivo simplesmente musicar uma fábula. Havia uma intenção de adaptar para seu tempo os símbolos e alegorias de um mundo cruel e castigado por uma Guerra Mundial, semelhante ao contexto no qual a obra de Orwell estava inserida. Mesmo não havendo uma guerra com envolvimento direto do Reino Unido em meados da década de 1970, o mundo vivia em uma polarização da Guerra Fria e a vida de Roger Waters era marcada por

\footnotetext{
${ }^{4}$ A paisagem sonora - soundscape" - tornou-se tanto um conceito quanto área de estudo que se preocupa em analisar o universo sonoro que rodeia as sociedades e cidades. Existem diferentes sons na paisagem, sejam eles de origem natural ou humana, através de sons industriais e tecnológicos. Na década de 1960, Murray Schafer liderou o World Soundscape Project na Simon Fraser University, com o objetivo de estudar a relação e a harmonia entre os sons, pessoas e ambientes, com foco na poluição sonora. O projeto também catalogou e guardou sons gravados de diversos ambientes e cidades e deu origem aos livros The Book of Noise (1968), The Tuning of the World (1977) e Handbook for Acoustic Ecology (1978).
} 
conflitos 5 . Há, portanto, mídias e formatos distintos abordando o mesmo assunto, talvez com objetivos políticos muito próximos: alertar seus leitores/ouvintes/espectadores para os perigos de uma sociedade comandada pelos escusos interesses políticos e econômicos de um grupo restrito.

\title{
Animals: Lado A
}

A primeira música do Lado A do álbum é uma balada, Pigs on the Wing (part 1), composta por Roger Waters para sua namorada, Carolyne. Trata-se de uma música curta, dedilhada em violão; o tom e clima sutis afagam o ouvinte em oposição à seriedade e à crueza das demais músicas. Com um minuto e vinte e cinco segundos, inicialmente formava uma única canção com a faixa que fecha o disco, sendo que elas foram divididas para tirar um pouco da frieza e do tom sério do álbum, dando-lhe um início e um fim coerente. A letra está reproduzida abaixo na íntegra.

\author{
Se você não se importasse com o que aconteceu comigo, \\ E eu não me importasse contigo \\ Nós andaríamos ziguezagueando \\ Nosso caminho através do aborrecimento e da dor \\ Ocasionalmente espiando através da chuva \\ Indagando qual dos vagabundos culpar \\ E observando porcos em voo (PIGS Part 1, 1977, tradução nossa). ${ }^{6}$
}

As palavras revelam uma atmosfera de intimidade e proteção, principalmente nas duas primeiras frases que apontam para um mútuo cuidado e apreço entre o casal. A voz do compositor e intérprete Waters acentua a tenacidade da letra, em uma performance sem forçar timbres ou tons aquém de sua voz "natural”, a mesma da fala. O violão

\footnotetext{
${ }^{5}$ O pai de Roger Waters, Eric F. Waters foi alvejado e morto em fevereiro de 1944 em uma missão durante a Segunda Guerra Mundial, em Anzio, na Itália. Já seu avô, George Henry Waters, morreu em 16 de setembro de 1916 em uma batalha na Primeira Guerra Mundial, quando seu pai tinha somente dois anos. $O$ fato de nunca ter conhecido o pai foi uma das inspirações para o disco que viria depois de Animals, o álbum duplo The Wall (1979).

6 "If you didn't care what happened to me/ And I didn't care for you/ We would zig zag our way through the boredom and pain/ Occasionally glancing up through the rain/ Wondering which of the buggers to blame/And watching for pigs on the wing". (PICS Part 1, 1977).
} 
eletroacústico é um contraponto calmo à música mecânica e ao ar pesado que permeia todas as outras três composições com nomes de animais (ROSE, 1995, p. 95).

Apesar da aparente leveza da música, ela está totalmente vinculada à temática do álbum, pois fala da necessidade de fortalecer as relações humanas frente às dificuldades sociais, o que fica evidente na frase: "andaríamos ziguezagueando nosso caminho através do aborrecimento e da dor".7 Esta primeira peça coloca a distopia zoomórfica dentro de um contexto real e palpável. A distopia, enquanto projeção pessimista e reflexiva, deve sempre remeter ao contexto político social no qual foi criada, não importando quais elementos alegóricos sejam empregados para ilustrar sua narrativa.

A música seguinte é Dogs, com dezessete minutos, a mais longa do disco, escrita por Roger Waters e David Gilmour, e a única em que ele também canta. O início é em fade in (o volume aumenta progressivamente), com duas guitarras tocando juntas compondo o ritmo sincopado junto com um teclado agudo que dá um tom de tensão, e que logo é percebido como a aproximação do primeiro cachorro. Há dois tipos diferentes de cães presentes da música Dogs: o primeiro, na voz de Gilmour, é o cão da disputa, que aspira alcançar o status do porco, e que, para tanto, vê na sociedade competitiva e injusta e na meritocracia os meios para alcançar seus objetivos; o segundo cão, interpretado por Waters, parece ter participado previamente do jogo capitalista, ter aceitado as regras sujas, porém, em algum ponto, reconheceu que estava sento usado pelo sistema, percebendo os problemas que esta postura pode acarretar.

A natureza intimidante do primeiro cachorro é retratada por diversos recursos sonoros, um deles é a entonação de David Gilmour sobre determinadas palavras, como o som do " $t$ " em toes e street, e mesmo o efeito de eco nos últimos versos da primeira parte.

Você tem que ser louco, tem que ter uma verdadeira necessidade Você precisa dormir pronto para o inesperado e quando você está na rua

\footnotetext{
7 As duas partes de Pigs on the Wing foram originalmente pensadas como uma única peça, cuja primeira versão recebeu um solo do guitarrista convidado Snowy White, entre as duas partes. White ainda tocou com a banda durante a turnê In the Flesh, e em trabalhos solo de Roger Waters e Richard Wright. Lançou mais de dez discos e colaborou com a banda irlandesa Thin Lizzy (MASON, 2013, p. 258).
} 
Você precisa ser capaz de distinguir a presa fácil com seus olhos fechados E depois movendo-se silenciosamente contra o vento e escondido Você precisa atacar no momento certo e sem pensar. (DOGS, 1977, tradução nossa) $)^{8}$

Nessa primeira estrofe, é possível perceber o mundo de disputa, cujo personagem não pode ver o outro como amigo, mas sim como alguém que precisa ser superado, ou mesmo aniquilado. A necessidade desse comportamento virulento acaba por estimular ainda mais a frieza do "cão". Como fica explicitado na estrofe seguinte, existem, ainda, vários códigos de conduta e comportamento que operam como distinção de classe e fomentadores de status.

E depois de algum tempo você pode treinar detalhes de estilo Como a gravata e um firme aperto de mão Um certo olhar nos olhos e um sorriso fácil. Você precisa ter a confiança das pessoas para quem você mente Para que quando elas virarem as costas Você tenha a chance de lhes enfiar a faca. (DOGS, 1977, tradução nossa) ${ }^{9}$

Uma das interpretações possíveis é a de que não há relação fora do mundo dos negócios, onde tudo é baseado no interesse, na troca de influências e objetivos escusos, como indica a continuação. Na canção, a última frase da estrofe acima recebe um reforço de backing vocal, o efeito de voz duplicada, que denota cumplicidade de diversas outras pessoas envolvidas neste sórdido sistema. A frase "to put your knife in", alongada com efeitos na voz de Gilmour, é cantada com ira, e o agudo da guitarra logo na última palavra reforça o sentido.

Em Animals, há a possibilidade de ascensão social, evidenciada pelo fato de que os cães desejam ser porcos, como podemos ouvir na última parte cantada por Waters, como nos versos reproduzidos abaixo. Percebe-se, de maneira poética e sutil, a agonizante

\footnotetext{
8 "You got to be crazy, gotta have a real need/ You gotta sleep on your toes, and when you're on the street/ You gotta be able to pick out the easy meat with your eyes closed/ And then moving in silently, down wind and out of sight/ You gotta strike when the moment is right without thinking". (DOGS, 1977)

9"And after a while, you can work on points for style/Like the club tie, and the firm handshake/ A certain look in the eye, and an easy smile /You have to be trusted by the people that you lie to /So that when they turn their backs on you/ You'll get the chance to put your knife in".
} 
transformação do animal. As primeiras duas frases ilustram o entupimento de veias e seu endurecimento, antecipando um ataque cardíaco, o qual será visto no primeiro porco da música seguinte, Pigs - three different ones. É uma descrição material de um animal que não mais é um cão, pois atingiu seu objetivo, "colheu o que plantou", e engordou fisicamente, o que levou ao entupimento das coronárias.

E quando você perde o controle, você colherá o que plantou $E$ à medida que o medo cresce, o sangue ruim para de correr e endurece E é tarde demais para perder o peso que você costumava precisar jogar por aí. (PIGS, 1977, tradução nossa) ${ }^{10}$

A última frase acompanha uma batida diferente na guitarra, sendo que a mudança na batida traduz a metamorfose animalesca. Os versos finais denotam novamente a solidão e tristeza do animal: "Então se afoga, enquanto afunda sozinho/Arrastado pra baixo como pedra (PIGS, 1977, tradução nossa) ${ }^{111}$. O final da palavra stone é repetido continuamente de forma abafada, em contraste com um crescente sintetizador, proporcionando uma atmosfera de desespero.

É mister notar que, nesta primeira parte, o eu lírico direciona o discurso a uma terceira pessoa, como se a instruísse a entrar no jogo. Este elemento é o outro cão, que passa a ser o centro da segunda parte. No interlúdio entre as duas estrofes, há uma sessão instrumental de contrabaixo e bateria que sugere que o primeiro cão foi deixado de lado com suas ideias, criando um retrato musical do cachorro seguinte. Os sintetizadores insinuam um mundo tecnológico moderno, com um tom bastante aterrador. A ênfase crescente dos instrumentos, em paralelo com latidos ao fundo, bem como assobios para supostamente chamar estes cães, podem ser interpretados como um ataque predatório e furtivo dos cães guiados por alguém. Após este trecho, há a volta do violão acústico nos mesmos acordes do início da música, igualmente crescente. Saindo do turbilhão do sintetizador, tem-se a impressão de que as coisas retornaram ao seu ciclo, até entrar a voz afoita de Waters.

\footnotetext{
10 "And when you lose control, you'll reap the harvest that you've sown/ And as the fear grows, the bad blood slows and turn to stone/And it's too late to lose the weight you used to need to throw around" (PIGS, 1977)

11 "So have a good drown, as you go down alone/Dragged down by the stone".
} 
Tenho de admitir que estou um pouco confuso

Às vezes me parece que eu estou sendo usado

Preciso ficar acordado, preciso tentar me livrar desse mal-estar crescente Se não impuser minha vontade, como posso encontrar a saída deste labirinto? (DOGS, 1977, tradução nossa) ${ }^{12}$

A primeira estrofe é uma resposta ao primeiro cão, e revela a incapacidade de perceber sua própria condição dentro do sistema capitalista. Apesar de notar que está sendo usado, ele procura encontrar seu lugar no mundo, mas não sabe como fazê-lo. A entonação da voz em awake e stand, em sincronia com o bumbo e o prato, indica que há, no segundo cão, uma segurança de si, como se ele ainda estivesse no controle de sua situação. Na estrofe seguinte, há uma contraposição a ele.

Surdo, mudo e cego, você apenas continua fingindo

Que todos são descartáveis e ninguém tem um amigo verdadeiro

E parece que para você a coisa a fazer seria isolar o vencedor

E tudo é feito sob o sol

E você acredita que lá no fundo todo mundo é um assassino. (DOGS,1977, tradução nossa) ${ }^{13}$

O segundo cão afirma que o primeiro tem falhado na sua tarefa de fingir ser um porco, semeando dúvida em sua tática de isolar o vencedor para alcançar seu status. No final das contas, nem tudo pode ser feito para se chegar ao ápice. Se é preciso esfaquear quando alguém lhe der as costas, logo, todos são assassinos em potencial. A briga entre os cães é retratada na forma de um longo interlúdio com guitarra e bateria distorcidas, que, no final, retornam com uma interpretação lenta e triste e com o lamento da guitarra.

Nicholas Schaffner, em um estudo sobre o Pink Floyd, percebeu outra referência literária dentro da última estrofe de Dogs. Trata-se de uma alusão ao poema Uivo, de 1956, do poeta Allen Ginsberg, pois começa cada frase, com final não rimado, com a palavra who (SCHAFFNER, 1991, p. 220). A estrofe assemelha-se ao célebre texto de

\footnotetext{
${ }^{12}$ "I gotta admit that I'm a little bit confused/ Sometimes it seems to me as if I'm just being used/ Gotta stay awake, gotta try and shake of this creeping malaise/ If I don't stand my own ground, how can I find my way out of this maze".

13 "Deaf, dumb, and blind, you just keep on pretending/ That everyone's expendable and no-one had a real friend/And it seems to you the thing to do would be to isolate the winner!".
} 
Ginsberg em várias dimensões: escrita, fonética e política. Escrita, pois o pronome pessoal repete-se tal qual no texto original. Fonética, porque o som produzido pela insistência na repetição da palavra produz um uivo - howl, em inglês. E, por último, política, porque tanto o disco quanto o poema demonstram as desilusões de seus autores com a sociedade na qual viviam, e abordam temas comuns, como o desapego aos bens materiais. ${ }^{14}$

Vejamos a última parte da canção.

Quem nasceu numa casa cheia de dor Quem foi educado a não cuspir no fã Quem recebeu ordens do homem Quem foi quebrado por pessoal treinado Quem foi vestido com coleira e corrente Quem levou um tapinha nas costas Quem foi apartado do rebanho Quem era apenas um estranho em casa Quem foi enterrado no final Quem foi encontrado morto ao telefone Quem foi arrastado para baixo pela pedra (DOGS, 1977 , tradução nossa) ${ }^{15}$

Waters aborda temas que serão aprofundados ainda mais no disco seguinte, The Wall, como o quanto o passado social do indivíduo e sua infância dolorosa podem determinar parte de seu psicológico. Assim, ser um cão em busca de ascensão pode estar

\footnotetext{
${ }^{14}$ Segue o trecho do poema. Note o início dos versos com "que", who, em comparação com a letra do Pink Floyd: "Que desnudaram seus cérebros ao céu sob o Elevado e viram anjos maometanos cambaleando iluminados nos telhados das casas de cômodos/ Que passaram por universidades com olhos frios e radiantes alucinando Arkansas e tragédias à luz de Blake entre os estudiosos da guerra/ Que foram expulsos das universidades por serem loucos \& publicarem odes obscenas nas janelas do crânio. [...] que caíram em prantos em brancos ginásios desportivos, nus e trêmulos diante da maquinaria de outros esqueletos/ Que morderam policiais no pescoço e berraram de prazer nos carros de presos por não terem cometido outro crime a não ser sua transação pederástica e tóxica/ Que uivaram de joelhos no metrô e foram arrancados do telhado sacudindo genitais e manuscritos/ Que se deixaram foder no rabo por motociclistas santificados e urraram de prazer/ Que enrabaram e foram enrabados por esses serafins humanos, os marinheiros, carícias de amor atlântico e caribeano/ Que transaram pela manhã e ao cair da tarde em roseirais, na grama de jardins públicos e cemitérios, espalhando livremente seu sêmen para quem quisesse vir" (GINSBERG, 2000, p. 25-28).

15 "Who was born in a house full of pain/ Who was trained not to spit in the fan/ Who was told what to do by the man/ Who was broken by trained personnel/ Who was fitted with collar and chain/ Who was given a pat on the back/ Who was breaking away from the pack/ Who was only a stranger at home/ Who was ground down in the end/ Who was found dead on the phone/ Who was dragged down by the stone" (DOGS, 1977).
} 
relacionado à falta de afeto e amor no seio familiar. Mais uma vez, a relação humana é colocada à frente das relações materiais.

\title{
Animals: Lado B
}

A primeira música do lado B é Pigs - Three different ones, com onze minutos e vinte e oito segundos; é dividida em três diferentes versos, cada um dedicado a um tipo de porco que povoa o mundo, e o Reino Unido em especial. Dos três, somente o último é explicitamente nomeado, mas os demais podem ser deduzidos. O primeiro som que se escuta na música é um grunhido de um porco, seguido de um sintetizador e uma sequência de quatro acordes no teclado, que transmite perigo e paranoia. Aos poucos, a progressão de um riff' ${ }^{16}$, junto à bateria e aos efeitos dos sintetizadores e teclado, cria uma atmosfera tensa que anuncia a chegada do primeiro porco, através da voz desesperada e irônica de Waters. Este primeiro personagem é o símbolo máximo de poder.

\author{
Grande homem, homem porco, ha ha, que falso você é \\ Seu próspero magnata, ha ha, que falso você é \\ E quando sua mão está sobre o seu coração \\ Você é quase uma boa risada \\ Perto de ser um piadista \\ Com sua cabeça enfiada no chiqueiro \\ Dizendo, "Continue cavando" \\ Uma mancha de porco em seu queixo gordo \\ O que você espera encontrar? \\ Quando você está na sua mina de porco. (PIGS, 1977, tradução nossa). ${ }^{17}$
}

Esse primeiro porco não é identificado diretamente. Porém, podemos intuir que se trata do estereótipo clássico do porco-capitalista, um homem de negócios ganancioso. Em uma entrevista realizada para a Rolling Stone em 2019, Waters afirmou que porco "é

\footnotetext{
${ }^{16}$ Originário do blues e do jazz e popularizado pelo rock, o riff é uma progressão de acordes, notas ou intervalos musicais, tocados repetidas vezes, tornando-se uma espécie de frase musical que acompanha a composição. Geralmente a música inicia com ele, mas não é uma regra.

17 "Big man, pig man, ha ha charade you are/ You well heeled big wheel, ha ha charade you are/And when your hand is on your heart/You're nearly a good laugh/ Almost a joker/With your head down in the pig bin/ Saying "Keep on digging."/ Pig stain on your fat chin/ What do you hope to find/ When you're down in the pig mine" (PIGS, 1977).
} 
qualquer empresário que está mais interessado em ganhar dinheiro do que em ter relacionamentos com outros seres humanos, o que pode ser mais recompensador do que acumular riqueza. Então, isso é para Steve Schwarzman e todos os outros. Eles são todos iguais, em geral." (WATERS, 2019, tradução nossa) ${ }^{18}$.

Stephen Schwarzman é um bilionário estadunidense que, em 1985, fundou com o colega Peter Peterson a empresa de fusões e aquisições Blackstone, que tornou-se a maior do mundo, com US\$ 538 bilhões em ativos. Schwarzman iniciou sua carreira em Wall Street no Lehman Brothers, empresa que foi o epicentro da crise imobiliária de 2008. De acordo com a lista da Forbes, é a $24^{\mathrm{a}}$ pessoa mais rica do mundo, com fortuna estimada em 20 bilhões de dólares (\#24 STEPHEN..., 2020).

Percebe-se que a música é um escárnio em terceira pessoa. Pode-se notar uma ligação com a música anterior, o que nos permite perceber que são cães que o descrevem dessa maneira, rindo dele, de seu porte gordo, sua posição social e postura mandatória: "Você é quase uma risada/ Você é quase uma risada/ Mas você é mesmo um lamento (PIGS, 1977, tradução nossa) $)^{19}$.

O próximo porco, que aparece parcialmente identificado no disco, é Margaret Thatcher, que ainda não era Primeira Ministra, mas já pontuava como Líder da Oposição.

Saco de ratos do ponto de ônibus, ha ha, que falsa você é

Sua megera fodida, haha, que falsa você é

Você irradia cacos de vidro frios

Você é quase uma boa piada

Quase vale um sorrisinho forçado

Você gosta da sensação do aço

Você é a maioral com seu pingente de chapéu

E é boa diversão com uma pistola

Você é quase uma piada

Você é quase uma piada

Mas você é um lamento. (PIGS, 1977, tradução nossa) ${ }^{20}$

\footnotetext{
${ }^{18}$ Nesta entrevista, Waters fala da sua nova versão para o clip de Pigs, para a turnê Us+Them, na qual um dos porcos seria o então presidente dos EUA, Donald Trump. "Big man, pig man," that's any businessman who's more interested in making money than they are in having relationships with other human beings, which might be more rewarding than accumulating wealth. So that's for Steve Schwarzman and all the rest of them. They're all the same, by and large". (WATERS, 2019)

19 "You're nearly a laugh/You're nearly a laugh/But you're really a cry".

20 "Bus stop rat bag, ha ha, charade you are/ You fucked up old hag, ha ha charade you are/ You radiate cold shafts of broken glass/You're nearly a good laugh/ Almost worth a quick grin/ You like the feel of steel/ You're
} 
A primeira palavra Rat Bag pode carregar um duplo significado ${ }^{21}$. Ao analisar a letra, percebe-se que a segunda frase faz referência a uma mulher. Mas a maior evidência de que se trata da política britânica está nas entrevistas da banda e nas performances ao vivo, pois Waters fazia um trocadilho, alterando velha, hag, por Mag, abreviação de Margaret. A terceira e a sétima frase indicam o vestuário da aristocracia britânica, como os cacos de vidro, que anunciam um brilho falso, e o chapéu, tradicional adereço de distinção de classe, usado por nobres e aristocratas britânicos em ocasiões especiais.

O que faz de Margaret Thatcher uma personalidade política tão singular para o grupo, a ponto de ser mencionada na música? Na verdade, ela personifica o medo (não somente do Pink Floyd) de uma onda conservadora que cresceu no ocidente a partir da década de 1970. Na época do lançamento de Animals, Thatcher era Líder da Oposição (1975-1979), título formal concedido ao líder do maior partido político que não esteja na base do governo vigente, no caso, o governo do trabalhista James Callaghan, que enfrentava problemas internos e externos. O sistema capitalista de produção entrava em uma profunda crise, com embargo na extração e distribuição de petróleo pelos países árabes, que gerou escassez e inflação no preço de combustíveis após 1973. Entre os efeitos globais da crise, é imperativo citar a desvalorização do dólar estadunidense durante o mandato do presidente Richard Nixon, bem como a alta inflação de diversos países industrializados.

A situação socioeconômica do Reino Unido era de alta inflação, greves e desemprego. Em 1974, o sindicato dos mineiros de carvão promoveu grandes blecautes, em resposta ao corte no fornecimento de combustível para as centrais térmicas, o que ajudou na queda do primeiro-ministro Edward Heath. Já o primeiro-ministro James Callaghan, eleito em 1976, líder do Partido Trabalhista e originário da classe operária, enfrentou o agravamento da crise nos sindicatos, desemprego e problemas no sistema público de saúde. Questões que a oposição conservadora de Margaret Thatcher soube

hot stuff with a hat pin; And you're good fun with a hand gun/ You're nearly a laugh/ You're nearly a laugh/But you're really a cry".

${ }^{21}$ Rat Bag, traduzida livremente como saco de lixo, também pode ser uma referência a um personagem de mesmo nome do programa de humor Monty Python, grupo humorístico do qual os integrantes do Pink Floyd eram fãs. 
explorar muito bem, levando-a a ser eleita primeira-ministra, em 1979. Não obstante, umas das ações de Thatcher foi aproximar-se do Instituto para Assuntos Econômicos (IEA), então sustentado por especuladores financeiros sob a doutrina de Friedrich von Hayek, Nobel de economia de 1974, e Milton Friedman, um dos mentores do neoliberalismo e Nobel de economia de $1976 . .^{22}$

Se o Pink Floyd propôs a revolução das ovelhas para colocar fim a "dor e aborrecimento" da sociedade animalizada, intelectuais marxistas britânicos já buscavam alternativas para o que chamavam de thatcherismo, como aponta Stuart Hall. O termo se refere a uma vertente de direita não velha no Reino Unido, mas que na década de 1980 havia se tornada hegemônica. Para impedir a continuidade desse regime, Hall sugeriu um contra-ataque proeminente dentro do Partido Trabalhista, com o apoio dos movimentos sociais que o sustentavam, sobretudo os sindicatos e a classe operária (HALL, 1980, p. 26).

Em seu segundo mandato, Margaret Thatcher esmagou as possibilidades de associação dos sindicatos, o que ela caracterizou como "inimigo interno" a ser derrotado. Por ora, é interessante ver que a figura do "Porco Maggie" personificava um risco da sociedade capitalista neoliberal: a dissolução das associações coletivas em prol de uma suposta liberdade individual, que acaba por gerar uma dependência maior das ovelhas para com os animais posicionados acima na pirâmide zoomórfica.

Durante o grande interlúdio instrumental que separa a entrada do último porco, podemos ouvir a "voz da guitarra". Trata-se de um recurso chamado de talk box, efeito de distorção e amplificação da guitarra através de um tubo. O som gutural do dispositivo, em contraste com o solo limpo e agudo da guitarra, simula uma conversa inaudível entre os porcos, como se um deles tentasse falar, mas nada que sai de sua boca pode ser compreendido. Este trecho abre e faz referência à personalidade britânica que fazia da voz e da retórica sua maior arma.

\footnotetext{
${ }^{22} \mathrm{O}$ nome em inglês é Institute of Economic Affairs, fundado em Londres no ano de 1955. A iniciativa partiu de Sir Antony Fisher, junto com o austríaco Friedrich Hayek, com o objetivo de reunir pensadores no mundo para espalhar a política econômica do livre mercado e evitar o alastramento do socialismo. Ao longo dos anos, o instituto publicou dezenas de jornais, revistas e livros, além de fazer seminários. Foi um dos principais precursores das políticas neoliberais. Entre seus membros estão doze recebedores do prêmio Nobel, como o próprio Hayek (MULLER, 1996, p. 88-110).
} 
Ei, você, Whitehouse
Haha, que falsa você é
Sua ratazana conservadora
Que charada você é
Você está tentando manter nossos sentimentos presos
Você é quase uma surpresinha agradável
Toda lábios cerrados e pés frios
E você se sente ofendida? (PIGS, 1977, tradução nossa) ${ }^{23}$

A citação direta nos leva a Mary Whitehouse, uma conservadora famosa que tinha grande audiência no Reino Unido nas décadas de 1960 e 1970. Whitehouse exemplifica, dentro da televisão britânica, um movimento conservador e reacionário às diversas bandeiras políticas que haviam sido colocadas na ordem do dia após o maio de 1968, sobretudo movimentos feministas e homoafetivos.

Whitehouse era educadora sexual e líder de diversos grupos cristãos, como o Clean-Up TV, de 1964, no qual criticava principalmente a BBC por considerar que havia em sua programação excesso de palavrões, violência e sexo. ${ }^{24}$ Entre as ações realizadas pela ativista estavam comícios, petições, campanhas e passeatas, bem como as muitas cartas que escrevia, seja para o primeiro-ministro, ministro da defesa, à família real, editores de revistas, artistas, escritores de peças de teatro e séries de televisão como Monty Phyton assumidamente ácidos e críticos -, além de Doctor Who e alguns jornalistas (THOMPSON, 2013, p. 37-60.). Dentro da música, artistas como Chuck Berry, The Beatles, Alice Cooper, e, claro, o Pink Floyd, foram alvos de suas críticas e tentativas de boicote (BLAKE, 2012, p. 272). O grupo era considerado como um dos degradantes elementos da tradição e cultura britânicas, constituindo um péssimo exemplo para os jovens, uma verdadeira maré diabólica. Os versos a seguir mostram essas acusações.

\footnotetext{
23 “Hey, you, whitehouse/ Ha ha charade you are/ You house proud town mouse/ Ha ha charade you are/ You're trying to keep our feelings off the street/ You're nearly a real treat/ All tight lips and cold feet/ And do you feel abused?".

${ }^{24}$ A própria Mary Whitehouse publicou diversos livros sobre os temas, como: Cleaning-up TV: From protest to Participation. Londres: Blandford, 1967; Who Does She Think She is?, Londres: New English Library, 1971; Whatever Happened to Sex? Londres: Wayland, 1977; Most Dangerous Woman?, Londres: Lion Hudson, 1977; Mightier Than the Sword. Londres: Kingsway Publication, 1985; An Autorbiography. Londres: Sidgwick \& Jackson, 1993.
} 
Você precisa deter a maré diabólica

E manter tudo isso do lado de dentro

Mary, você é quase um docinho

Mary, você é quase um docinho

Mas você é um lamento. (PIGS, 1977, tradução nossa) $)^{25}$

Depois de um longo solo de guitarra no último verso, com a música quase terminando em fade out, ouve-se o teclado bucólico de Richard Wright e os efeitos de fita com balidos de ovelhas. O som desses animais, na música dos porcos, tem a clara intenção de ligar as duas composições e, consequentemente, as duas classes.

A terceira música é Sheep, na qual toda a parte lírica é, novamente, cantada em terceira pessoa, mais uma vez revelando a voz dos cães. A música tem dez minutos e vinte segundos, e inicia somente com balidos e com os teclados de Wright durante o primeiro minuto. Há uma atmosfera bucólica e calma, o teclado toca em notas que parecem soar aleatórias, formando mais um passeio despreocupado do que uma melodia coerente. Através da teoria de Murray Schafer, percebemos que esses elementos permitem "enxergar" uma visão de um campo agropastoril; o badalar dos sinos, os animais pastando, barulhos de pássaros, e o próprio teclado são itens que compõem essa “paisagem sonora”. O uso desses sons servepara estabelecer a natureza pacífica desses animais. No segundo minuto, o contrabaixo de Waters começa a crescer em uma marcação que quebra a tranquilidade do som, e logo o teclado compassa suas notas com este instrumento e com a bateria. Pouco antes dos dois minutos acabarem, a interpretação do vocalista dá-se de forma apressada: "Passando inofensivamente seu tempo no pasto/ Vagamente atento a um certo desconforto no ar." (SHEEP, 1977, tradução nossa) $)^{26}$.

A letra continua com um alerta contra os perigosos cães - "É melhor você tomar cuidado/ Pode haver cães por aí /Eu examinei o Jordão e vi que as coisas não são o que

\footnotetext{
25 "You gotta stem the evil tide/ And keep it all on the inside/ Mary, you're nearly a treat/ Mary, you're nearly a treat But you're really a cry".

26 "Harmlessly passing your time in the grassland away/ Only dimly aware of a certain unease in the air" (SHEEP, 1977).
} 
parecem." (SHEEP, 1977, tradução nossa)27, - descrevendo em palavras a sensação de angústia apresentada pelos instrumentos. Baseado em um estudo comparativo, podemos indagar que terceira frase pode ser uma referência à música Swing Low, Sweet Chariot, que em 1975 foi regravada como um reggae por Eric Clapton; a autoria original é desconhecida e provém das tradicionais negro spiritual ou spiritual songs (música espiritual, gospel, negra, em tradução livre), canções compostas por escravos afrodescendentes nos EUA. Neste contexto, a religião aparece como opressora, ao mesmo tempo em que promete a libertação dos problemas e da situação social. Não por acaso, a ovelha aparece na Bíblia como símbolo de fé, formando os crentes um verdadeiro rebanho, reconfortado e guiado por Jesus, sendo mais tarde sacrificada em favor da purgação dos pecados da humanidade.

O que você ganha fingindo que o perigo não é real?
Submissos e obedientes vocês seguem o líder
Descendo pelos trauteados corredores, em direção ao vale do aço.
Mas que surpresa!
Um último olhar choca seus olhos
Agora as coisas são o que realmente parecem ser.
Não, isto não é um pesadelo. (SHEEP, 1977, tradução nossa) ${ }^{28}$

Nas primeiras frases desse verso percebe-se a deferência e obediência dessa classe para com seus líderes, que os guiam até a realidade da servidão e do trabalho. Em seguida, as ovelhas parecem passar por uma espécie de despertar inicial. Neste momento, um acorde de guitarra segue logo após o final de cada verso. Os efeitos de eco aumentam e a voz soa irônica, como se o narrador estivesse rindo enquanto percebe a reação das ovelhas.

Há uma paródia do Salmo 23, da Bíblia, na qual é citado o “vale do aço” no lugar de o "vale da sombra da morte". O final deste trecho é cantado com ainda mais veemência e ira, ao passo que o arranjo instrumental se torna mais preenchido e vigoroso.

\footnotetext{
27 "You better watch out/ There may be dogs about/ I've looked over Jordan, and I have seen/ Things are not what they seem".

28 "What do you get for pretending the danger's not real/ Meek and obedient you follow the leader/ Down well trotten corridors, into the valley of steel/ What a surprise!/A look of terminal shock in your eyes/ Now things are really what they seem/No, this is no bad dream".
} 
Concomitante com o final dos versos, há uma diminuição da bateria até tudo parar de súbito. Antes da paródia do Salmo 23, o instrumental recorre aos mesmos sons da música Pigs, um agudo som de alerta de uma sirene, feito pelo teclado, cresce em paralelo com a guitarra mais limpa. Em seguida, perto dos cinco minutos e meio, uma nova calmaria, quebrada apenas por teclados tensos e o mesmo contrabaixo galopante do início da música. O salmo é recitado com efeito de vocoder, aparelho que dá a voz humana um efeito sintetizado, quase robótico. ${ }^{29}$

Toda estrutura que permite a opressão também cria condições de seu próprio fim, o que nos é sugerido nos versos seguintes.

Balindo e balbuciando, caímos em seu pescoço com um grito Onda após onda de vingadores insanos Marcham alegremente da obscuridade para um sonho. Você já ouviu as notícias?

Os cães estão mortos!

É melhor você ficar em casa

E fazer o que lhe mandarem

Caia fora da estrada se quiser continuar vivo. (SHEEP, 1977, tradução nossa) ${ }^{30}$

O primeiro cão, narrador dessa música, incita as ovelhas a se rebelarem. Após os ataques ao pescoço dos porcos, a terceira frase levanta possibilidades de interpretação: Foi tudo um sonho, uma projeção utópica? Ou trata-se realmente de sair da obscuridade de sua condição de subalternidade para uma nova ordem social, ao libertar-se dela?

Seja como for, as notícias da morte dos cães, os mesmos traidores do sistema que incitaram a revolta, e da volta à passividade, ao medo e à tensão por parte das ovelhas,

\footnotetext{
${ }^{29}$ Vocoder vem do inglês (voice operated recorder); foi inventado pelo físico Homer W. Dudley, do Bell Labs, em Nova Jersey, EUA, em 1939, para ser utilizado na área de telecomunicações. Trata-se de uma caixa com um pequeno teclado acoplado a um microfone que capta a voz humana e a modifica para uma sintetizada, o que resulta em uma voz robotizada, metalizada ou computadorizada. Aliás, a própria ideia de voz de um robô foi construída a partir das alterações no timbre humano pelo vocoder. Na década de 1960, várias bandas utilizaram este recurso, como The Beatles.

30 "Bleating and babbling we fell on his neck with a scream./ Wave upon wave of demented avengers/ March cheerfully out of obscurity into the dream./ Have you heard the news?/ The dogs are dead!/ You better stay home/ And do as you're told,/ Get out of the road if you want to grow old".
} 
nos apontam o resultado frustrado da revolução. Não pode haver espaço para final feliz nas narrativas distópicas, ainda que exista uma fagulha de esperança.

Em entrevista para o jornalista da Melody Maker, Karl Dallas, Waters explicou parte da inspiração para essa música.

Foi o meu senso do que aconteceu na Inglaterra, como foi no verão passado com os motins... em Brixton e Toxteth... isso tinha acontecido antes em Nothing Hill, no início dos anos sessenta. E isso vai acontecer novamente. Isso sempre acontece. Há muitos de nós no mundo e nos tratamos mal uns aos outros. Nós ficamos obcecados com produtos e não há suficiente deles. [...] se estivermos convencidos que é importante possuí-los, que nada somos sem eles, mas que não são suficientes, as pessoas que não os tiverem, vão ficar com raiva. Contentamento e descontentamento seguem de muito perto a ascensão e queda no gráfico da recessão e expansão mundial. (DALLAS, 1987, p. 127)

Há uma simplificação na fala de Waters para se referir às diferentes formas de levantes que aconteceram no Reino Unido em diversos locais, entre as décadas de 1950 e 1980. Além de questões materiais, como desejar bens de consumo e de não poder comprar, tais movimentos revelam grandes problemas com imigrantes, movimentos neonazistas, altas taxas de desemprego e violência policial nas comunidades negras e pobres da Inglaterra. Começaremos pelo evento mais próximo da banda, em 30 de agosto de 1976, durante o tradicional carnaval afro-caribenho do bairro londrino de Notting Hill, quando um jovem imigrante que havia roubado uma carteira foi desproporcionalmente repreendido e agredido por policiais. Em resposta, a população negra recebeu a polícia metropolitana de Londres com cones, tijolos e paus. Os residentes do bairro multiétnico justificavam suas ações em virtude do racismo institucionalizado contra os negros e imigrantes. Na ocasião, mais de cem policiais foram hospitalizados e sessenta civis presos. O bairro já havia sido palco de outro confronto, em 1958, entre fascinados por ideias neonazistas contra afrodescendentes, que imigraram após a Segunda Guerra.

A canção que fecha o álbum é a segunda metade da primeira, Pigs on the Wing (Part 2). Curiosamente, essas foram as primeiras letras do Pink Floyd a falarem diretamente sobre o amor entre duas pessoas. Waters, ao ser questionado sobre a leveza 
das duas peças frente às outras três músicas, respondeu: “Era muito necessário, caso contrário o álbum teria sido apenas uma espécie de... grito! Você sabe, de raiva!" (CAPITAL, 1977, tradução nossa) ${ }^{31}$.

A música repete o tempo, arranjos, harmonia e a melodia daquela que abre o disco. Entretanto, o que nos é caro aqui é a análise lírica, para compreender como a distopia é encerrada.

Você sabe que eu me preocupo com você

E eu sei que você também se preocupa comigo

Assim eu não me sinto só

Nem sinto o peso da pedra

Agora que eu encontrei um lugar seguro

Para enterrar meu osso

E qualquer idiota sabe que um cão precisa de um lar

Um abrigo contra os porcos que voam. (PIGS part two, 1977, tradução nossa) $)^{32}$

A calmaria reina nas relações entre os bichos, pois se nota um evento posterior à revolução, sendo que o casal precisa de abrigo, e encontraram esse abrigo um no outro. Mas aqui há uma novidade: eles fazem parte do segundo tipo de cães, como mostra a necessidade em enterrar seu osso. Eles perceberam os perigos de serem arrastados para a solidão, como aconteceu com o cão raivoso em Dogs. O afeto da música composta por Waters para sua namorada permite identificar o próprio compositor como pertencente à mesma classe de animais.

\section{Animals e Revolução dos Bichos}

O livro de George Orwell (2007) narra a história da Granja do Solar, comandada pelos humanos Sr. Jones e seus subordinados. O porco Major reúne todos os animais,

\footnotetext{
31 "It was very necessary, otherwise the album woud've just been a kind of [...] scream you know, of rage!" (CAPITAL, 1977).

32 "You know that I care what happens to you/ and I know that you care for me too/so I don't feel alone/or the weight of the stone / now that I've found somewhere safe/ to bury my bone/ And any fool knows a dog needs a home/ a shelter from pigs on the wing" (PIGS part two, 1977).
} 
entre burros, cavalos, vaca, três cachorros, galinhas, ovelhas, rato, cabra, gata, patos e corvo, no celeiro para um profético pronunciamento sobre o futuro das relações entre os homens e os animais na granja e em toda Inglaterra. Segundo Major, nenhum animal é livre, todos apenas recebem o mínimo de alimento necessário para continuarem respirando e utilizarem sua força ao máximo para o trabalho. A reunião termina, então, com o ensinamento de uma canção que se tornaria hino da revolução: "Bichos da Inglaterra". Dois jovens porcos assumem as funções de líderes - Napoleão e Bola-deNeve - seguidos pelo eloquente suíno Garganta. Aos poucos, os animais acabam esquecendo os ideais da Revolução e os mandamentos que guiavam o Animalismo, ideologia que regia a fazenda.

No final, os animais da Granja do Solar - a fazenda, por ordem de Napoleão, havia retomado o antigo nome - já não sabiam se eram mais felizes no tempo de Jones ou naquele momento. Na verdade, podiam jurar que trabalhavam mais e recebiam menos ração que antes. O ditador Napoleão, cujas aparições eram cada vez mais raras, cercadas de pompa e dos violentos cães, agora aparecia vestido com as antigas roupas de Jones e sua porca preferida usava as roupas de domingo da esposa de Jones. Também passou a andar sobre duas patas, como os demais porcos, depois de um longo treinamento capitaneado por Garganta. O livro termina com uma reunião entre os porcos e os humanos donos das granjas vizinhas sentados na sala de jantar, celebrando a prosperidade da Granja do Solar e sua boa relação com os vizinhos.

De acordo com a linguista Giezi Alves de Oliveira,

As metáforas concebidas a partir da imagética animal possuem papel relevante nas narrativas e, consequentemente, na comunicação humana, principalmente como recurso didático para implementação e refinamento de discursos. [...]. As fábulas que envolvem animais mesclam as características e comportamentos humanos. Para a esperteza, normalmente as fábulas utilizam a raposa; para a força, o cavalo, o touro ou o leão; para a vilania, a cobra, mas também a raposa; para a sabedoria, a coruja. Para descrever atitudes idiotas, o asno ou a toupeira são os animais mais representativos; para a velocidade o leopardo; para a lealdade, o cão; para o trabalho, esforço e espírito de união, a formiga. (OLIVEIRA, 2016, p. 180) 
Ao optarem pela fábula como forma narrativa, tanto Orwell quanto o Pink Floyd tinham como propósito disseminar uma moral, um sentido político, uma estratégia. E a fábula, justamente por sua linguagem e interpretação mais acessíveis que outros textos políticos, como manifestos, teorias e tratados, podia fazer a mensagem ser entendida por um público maior, especialmente operários e pessoas de classes mais baixas, que não possuíam uma educação básica ou mesmo acesso à leitura. Porém, enquanto o livro, escrito no contexto da Segunda Guerra, discorre sobre os horrores e perigos do stalinismo e tinha como meta denunciar os desvios de conduta dos líderes da Revolução Russa33, o disco do Pink Floyd não possuía o mesmo público nem os mesmos objetivos do livro. Mas há uma clara mensagem ao se criar uma fábula distópica que remeta ao texto de George Orwell: a necessidade de expor, de alguma forma, a exploração humana, agora em outro contexto - as contradições do capitalismo e as mazelas que acarretam nas relações sociais no mundo contemporâneo.

Assim, valores, questões e paradigmas estão presentes tanto em A Revolução dos Bichos quanto em Animals, entre os quais destaco as relações entre a tradição e a renovação e entre o coletivismo e o individualismo em contextos diferentes: o primeiro, na ditadura stalinista, na União Soviética, como no livro; o segundo, na democracia liberal burguesa ocidental em franca ascensão neoliberal. Com esse horizonte, ambas apresentam discussões sobre conflitos sociais e paz, condições dignas de trabalho, moralidade e conflitos de classe que regem as sociedades, cada qual com seus líderes políticos, dinâmicas internas e seus agentes mantenedores do status quo. São duas obras distintas que falam de revoluções iminentes, mas cada qual esquadrinha uma forma ideal de organização social, política e econômica na busca de mais justiça social.

As obras, portanto, mantêm as estruturas básicas da distopia enquanto gênero narrativo, possível de ser adaptado em plataformas díspares. Baseado em um clássico literário do gênero, o décimo álbum do Pink Floyd apresenta uma visão crítica e

\footnotetext{
33 O título original do livro é Animal Farm: A Fairy Story, e foi escrito entre 1943 e 1944 e lançado no ano seguinte. Foi publicado em mais de 60 países e recebeu adaptações para o cinema como a animação dirigida e produzida por Joy Batchelor e John Halas (Bathelor and Halas, 1954) e o filme feito para televisão, rodados com animais reais, Animal Farm (Hallmarks Films, 1999), dirigido por John Stephenson e roteirizado por Alan Janes.
} 
pessimista de seu tempo e pode ser considerado uma distopia clássica ou típica. Isso é evidenciado tanto nos elementos musicais, como o instrumental, como na voz e na parte lírica, quanto nas performances, que reforçam os elementos derrotistas comuns nas distopias. Aqui, eles se mostram inquietantes, soturnos e pesados. Por meio da necessidade das ligações humanas e das afeições frente a um mundo frio e tecnológico, a obra não apresenta uma alternativa para o capitalismo, mas há uma malograda fagulha revolucionária, e demonstra o desconforto nocivo e corrosivo inerente a esse modo de vida.

\section{Referências}

\#24 STEPHEN SCHWARZMAN. Forbes, [Jersey City], c2020. Disponível em: https://www.forbes.com/profile/stephen-schwarzman/?sh=5be6fo72234a. Acesso em: 01 dez. 2020.

BLAKE, Mark. Nos bastidores do Pink Floyd. São Paulo: Generale, 2012.

CAPITAL Radio. The Pink Floyd Story. BBC, [S.I.: s.n.], 21 jan. de 1977. 1 vídeo (ca 15 min). Publicado pelo canal The Mudman. Disponível em:

https://www.youtube.com/watch?v=wJgXGEnpd_g. Acesso em: 28 set. 2020.

DALLAS, Karl. Bricks in the wall. Nova lorque: Shapolsky Publishers, 1987.

DOGS. Intérprete: Pink Floyd. In: ANIMALS. Intérprete: Pink Floyd. Londres: Harvest: Columbia, 1977. 1 disco vinil, lado A, faixa 2 (17:03 min).

GINSBERG, Allen. Uivo: Kaddish e outros poemas. Porto Alegre: L\&PM Pocket, 2000.

HALL, Stuart. Thatcherism a new stage? Marxism Today, London, v. 24, n. 2, p. 26-28, feb. 1980.

MASON, Nick. Inside out: a verdadeira história do Pink Floyd. São Paulo: Escrituras, 2013.

MORE, Thomas. Utopia. São Paulo: Editora Lafonte, 2017.

MULLER, Christopher. The Institute of Economic Affairs: undermining the post-war consensus. Contemporary British History, [S.I.], v. 10, n. 1, p. 88-110, 1996. 
NAPOLITANO, Marcos. História \& música. Belo Horizonte: Autêntica, 2002.

OLIVEIRA, Giezi Alves de. A Narrativa que nos guia, o discurso que emerge: um estudo acerca do processamento cognitivo do significado em fábulas. 209f. 2016. Tese (Doutorado em Estudos da Linguagem) - Universidade Federal do Rio Grande do Norte, Natal, 2016.

ORWELL, George. A revolução dos bichos. São Paulo: Cia das Letras, 2007.

POVEY, Glenn. The complete Pink Floyd: the ultimate reference. Londres: Sterling, 2016.

PIGS on the Wing (part 1). Intérprete: Pink Floyd. In: ANIMALS. Intérprete: Pink Floyd. Londres: Harvest Records, 1977. 1 disco vinil, lado A, faixa 1 (1:25 min).

PIGS on the Wing (part 2). Intérprete: Pink Floyd. In: ANIMALS. Intérprete: Pink Floyd. Londres: Harvest Records, 1977. 1 disco vinil, lado B, faixa 3 (1:23 min).

PIGS - Three different ones. Intérprete: Pink Floyd. In: ANIMALS. Intérprete: Pink Floyd. Londres: Harvest: Columbia, 1977. 1 disco vinil, lado B, faixa 1 (11:25 min).

ROSE, Philip Anthony. Which one's pink? Londres: Collector's Guide Publishing, Inc, 1995.

SCHAFER, Murray. O ouvido pensante. São Paulo: Edunesp, 1991.

SCHAFFNER, Nicholas. A saurcerful of secrets: the Pink Floyd odyssey. New York: Delta, 1991.

SHEEP. Intérprete: Pink Floyd. In: ANIMALS. Intérprete: Pink Floyd. Londres: Harvest: Columbia, 1977. 1 disco vinil, lado B, faixa 2 (10:25 min).

THOMPSON, Ben. Ban this filth!: letters from the Mary Whitehouse archive. Londres: Faber and Faber, 2013.

THE PINK FLOYD AND SYD BARRETT STORY. Direção de John Edginton. Produção de Basil Comedy. Música: Pink Floyd e Syd Barrett. Londres: BBC: Otmoor Production, 2001. (60 min.), son., color.

WALSER, Robert. Running with the devil: power, gender and madness in heavy metal music. Middletown: Wesleyan University Press, 1993.

WATERS, Roger. Roger Waters talks 'us + them' film, why Pink Floyd's songs remain relevant. [Entrevista cedida a] Kory Grow. Rolling Stone, [San Francisco], 30 sept. 2019. 
Disco Animals do Pink Floyd: uma distopia sobre animalização do sistema capitalista e a democracia liberal burguesa

Franco Santos Alves da Silva

Disponível em: https://www.rollingstone.com/music/music-features/roger-waters-usthem-film-interview-889933/. Acesso em: $01 \mathrm{dez} .2020$

Recebido em: 30/06/2020

Aprovado em: 21/12/2020

Universidade do Estado de Santa Catarina - UDESC

Centro de Ciências Humanas e da Educação - FAED

PerCursos

Volume 21 - Número 47 - Ano 2020 revistapercursos@gmail.com 